\title{
Assessing and improving self-reporting of male circumcision in Zambia and Swaziland
}

\author{
Paul C. Hewett \\ Population Council \\ Nicole Haberland \\ Population Council \\ Barbara Mensch \\ Population Council \\ Louis Apicella \\ Population Council
}

Follow this and additional works at: https://knowledgecommons.popcouncil.org/departments_sbsr-hiv

Part of the Community Health and Preventive Medicine Commons, Health Services Research Commons, Immune System Diseases Commons, International Public Health Commons, Medicine and Health Commons, Public Health Education and Promotion Commons, and the Virus Diseases Commons How does access to this work benefit you? Let us know!

\section{Recommended Citation}

Hewett, Paul C., Nicole Haberland, Barbara Mensch, and Louis Apicella. 2012. "Assessing and improving self-reporting of male circumcision in Zambia and Swaziland," Population Council Research and Evaluation of Male Circumcision Scale-Up Report. New York: Population Council. 


\section{Assessing and Improving Self-Reporting of Male Circumcision in Zambia and Swaziland}

Population Council Research and Evaluation of Male Circumcision Scale-Up—Report \#2
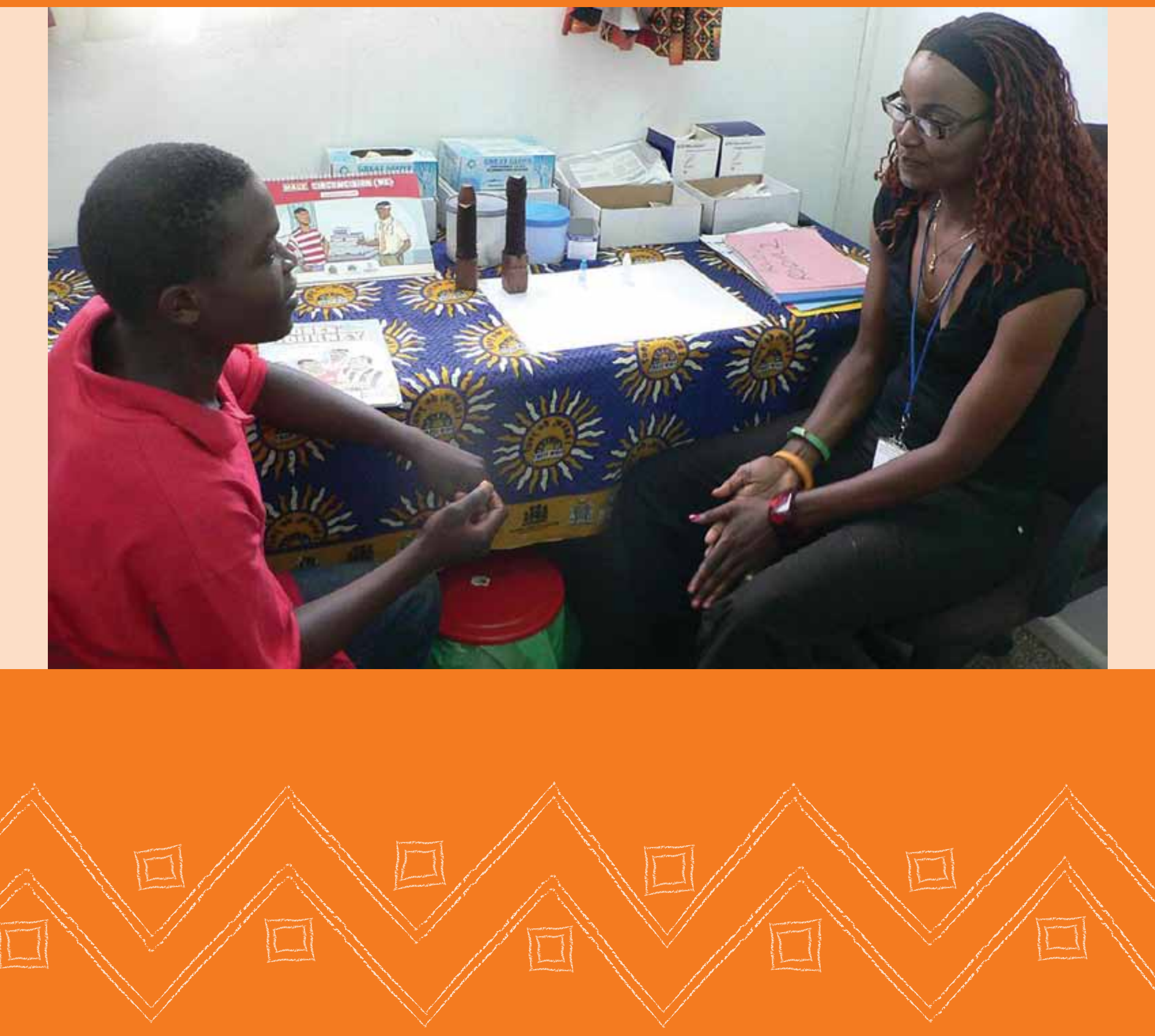



\title{
Assessing and Improving Self-Reporting of Male Circumcision in Zambia and Swaziland
}

\author{
Paul C. Hewett, Nicole Haberland, \\ Barbara S. Mensch, and Lou Apicella
}

Population Council

Population Council Research and Evaluation of Male Circumcision Scale-Up-Report \#2

Updated June 2012

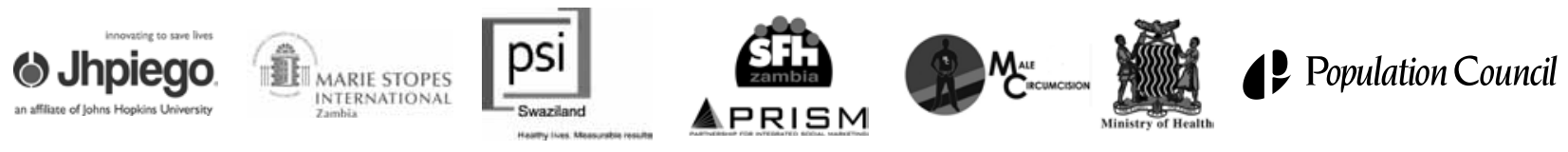




\title{
ACKNOWLEDGMENTS
}

The principal investigator for this study was Nicole Haberland (Population Council, New York). Co-investigators were Lou Apicella, Barbara S. Mensch, Paul C. Hewett, John Manda (Population Council, Swaziland; Population Council, New York; Population Council, Zambia; and Society for Family Health, Zambia respectively). Study coordination was overseen by Alfred Adams (Population Council, Swaziland) and Kelvin Munjile (Population Council, Zambia). Data collection team members are listed in Appendix D. Paul C. Hewett directs the Council's MC research and evaluation program, and Naomi Rutenberg (Population Council, Washington D.C.) serves as Senior Technical Advisor.

The research team would like to thank the other collaborating institutions in the MC Partnership for their active input and support of this study: Steve Gesuale, Hayden Hawry, Nicholas Shiliya (Society for Family Health, Zambia); Jessi Greene (PSI, Swaziland); Marie Stopes International, Zambia; and Jhpiego. We would also like to thank the Zambia Ministry of Health for their support of the study and review of the study findings.

We gratefully acknowledge the contributions of Barbara Miller, Samir Souidi, Stan Mierzwa, Kavitha Valasa, Sherry Hutchinson, Roman Zadorozhny, and Max Gill in the implementation of the project and the preparation of the report.

The research team is especially grateful to the participants, parents, and guardians who generously gave their time to participate in the study. Special thanks to the staff at the participating health centers for facilitating study implementation.

This report includes data published in journal article. Hewett, P.C. et al. 2012. "The (mis) reporting of male circumcision status among men and women in Zambia and Swaziland: A randomized evaluation of interview methods," PLoS ONE 7(5): e36251.

doi:10.1371/journal.pone.0036251.

This study was conducted under a sub-grant from Population Services International (PSI) through the MC Partnership, which is sponsored by PSI with support from the Bill \& Melinda Gates Foundation.

\footnotetext{
12 Population Council The Population Council conducts research worldwide to improve policies, programs, and products in three areas: HIV and AIDS; poverty, gender, and youth; and reproductive health. www.popcouncil.org
}

\begin{abstract}
Suggested citation: Hewett, Paul C., Nicole Haberland, Barbara S. Mensch, and Lou Apicella. 2011. "Assessing and improving self-reporting of male circumcision in Zambia and Swaziland," Population Council Research and Evaluation of Male Circumcision Scale-Up-Report \#2. New York: Population Council.
\end{abstract}

Published in June 2011. Updated June 2012. Copyright (C2011, 2012 The Population Council, Inc.

This document may be reproduced in whole or in part without permission of the Population Council provided full source citation is given and the reproduction is not for commercial purposes. 


\section{TABLE OF CONTENTS}

ABBREVIATIONS AND ACRONYMS ii

EXECUTIVE SUMMARY

Background 1

Study Objectives 1

Methods 2

Results 3

Conclusions and Recommendations 4

INTRODUCTION 6

$\begin{array}{ll}\text { The Male Circumcision Partnership } & 6\end{array}$

$\begin{array}{ll}\text { Background } & 7\end{array}$

Study Objectives 9

$\begin{array}{ll}\text { METHODS } & 10\end{array}$

$\begin{array}{lr}\text { Ethical Considerations } & 10\end{array}$

$\begin{array}{lr}\text { Sample } & 10\end{array}$

$\begin{array}{ll}\text { Study Design } & 11\end{array}$

$\begin{array}{ll}\text { RESULTS } & 14\end{array}$

$\begin{array}{lr}\text { Participant Characteristics } & 14\end{array}$

$\begin{array}{lr}\text { Numeracy and Literacy Assessment } & 16\end{array}$

Knowledge of Male Circumcision and HIV 17

$\begin{array}{ll}\text { Physical Examination Refusals } & 17\end{array}$

$\begin{array}{lr}\text { Circumcision Status of Participants } & 18\end{array}$

Misreporting of Circumcision Status 19

Multivariate Assessment of Interview Methods 22

Multivariate Assessment of Illustration $\quad 23$

CONCLUSIONS AND RECOMMENDATIONS 25

Appendix A Study Sample Sizes by Key Indicators $\quad 27$

Appendix B Description of Audio Computer-Assisted Self-Interview (ACASI) 28

Appendix C Literacy and Numeracy Evaluation $\quad 29$

$\begin{array}{ll}\text { Appendix D Study Fieldwork Teams } & 30\end{array}$

$\begin{array}{ll}\text { REFERENCES } & 31\end{array}$ 


\section{ABBREVIATIONS AND ACRONYMS}

$\mathrm{ABC}$

ACASI

AE

AES

AIDS

AOR

CI

CT

EDC

FTFI

HIV

HPV

IRB

Jhpiego

$\mathrm{MC}$

MC Partnership

$\mathrm{MOH}$

MSI

NGO

OR

PC

PEPFAR

PI

PSI

SFH

SSI

STD

STI

UNAIDS

UNZA

$\mathrm{UTH}$

WHO

YWCA

ZDHS

ZSBS abstinence, be faithful, use condoms

audio computer-assisted self-interview

adverse event

advanced encryption standard

acquired immune deficiency syndrome

adjusted odds ratio

confidence interval

HIV counseling and testing

electronic data capture

face-to-face interview

human immunodeficiency virus

human papillomavirus

institutional review board

Johns Hopkins International Health NGO

male circumcision

Male Circumcision Partnership

Ministry of Health

Marie Stopes International

non-governmental organization

odds ratio

Population Council

President's Emergency Plan for AIDS Relief

principal investigator

Population Services International

Society for Family Health

semi-structured interview

sexually transmitted disease

sexually transmitted infection

The Joint United Nations Programme on HIV/AIDS

University of Zambia

University Teaching Hospital (Lusaka)

World Health Organization

Young Women's Christian Association (of Zambia)

Zambia Demographic and Health Survey

Zambia Sexual Behavior Survey 


\section{EXECUTIVE SUMMARY}

\section{Background}

The Male Circumcision (MC) Partnership was established with the support of the Bill and Melinda Gates Foundation and PEPFAR to scale up MC services in Zambia, in collaboration with the Zambian government. The MC Partnership is a five-year project led by Population Services International (Society for Family Health, in Zambia), in partnership with Jhpiego, Marie Stopes International (MSI), and the Population Council. The MC Partnership works closely with the Ministry of Health (MOH) in Zambia to advance the National MC Policy and Strategy to scale up MC services in the public, private, and non-governmental organization (NGO) sectors, and to focus on increasing demand for $\mathrm{MC}$ services through social marketing and behavior change communication campaigns. The MC Partnership emphasizes research and evaluation to measure uptake in $\mathrm{MC}$ services, ensure that quality of services is high, and maximize the effectiveness and efficiency of MC services. At the time of this study (2009 and 2010), the MC Partnership was also active in Swaziland and operated with similar objectives.

\section{Study Objectives}

The ultimate objective of this study is to provide researchers and program managers with evidence-based recommendations for the collection of self-reported data on MC status through an assessment of different methods to describe and explain MC. Specifically, the study assessed tools for improving the reporting of circumcision status, including a) a detailed verbal description of male circumcision, b) an illustration of a circumcised and an uncircumcised penis, and c) computerized self-interviewing technology.

The accurate measurement of MC status is critical for both cross-sectional and longitudinal studies that assess HIV risk as well as for HIV prevention trials. Given the logistical constraints entailed and the resources required to perform physical examinations to ascertain circumcision status, particularly in household-based surveys, there is a need to assess the quality of data obtained from self- and partner reports of MC status. The literature indicates varying degrees of misreporting of circumcision status by males. Among men, rates of misreporting range from near zero (Lavreys et al. 1999) to 50 percent (Thomas et al. 2010). To our knowledge, no quantitative studies have assessed the accuracy of reports by females of their partner's circumcision status.

Discrepancies between self-reports and actual circumcision status may be a function of 1) knowledge-i.e., a poor understanding of what is meant by circumcision, 2) reporting biases due to social norms, and/or 3) physical differences-i.e., variation in the length of the foreskin or in the completeness of circumcision. Erroneous self-reports could lead to misleading findings regarding MC uptake and its impact on HIV. Moreover, understanding the quality of women's reporting is critical for HIV prevention trials that enroll women, since the circumcision status of their male partner is an important risk factor for STI/HIV. 


\section{Methods}

The study was conducted from July 2009 to May 2010. It was implemented sequentially in three sites/phases, first in urban Zambia (Lusaka), second in urban Swaziland (Mbabane and Matsapha), and finally in rural Zambia (selected wards within 20 kilometers of Lusaka). Men aged $18-50$ and their female partners, as well as adolescent boys aged 13-17, were eligible. Study participants were recruited from clients visiting HIV counseling and testing (CT) sites and health centers, and from the communities surrounding these clinics.

The study design varied by site and phase, with preliminary results from each site/phase informing the next stage of data collection. At all phases, participants were randomized to one of three experimental arms:

Urban Zambia (Lusaka)

1. Face-to-face interview (FTFI): Simple description

2. FTFI: Simple description + illustration

3. Audio computer-assisted self-interview (ACASI): Simple description + illustration

Urban Swaziland (Mbabane and Matsapha)

1. FTFI: Detailed description

2. FTFI: Detailed description + illustration

3. ACASI: Detailed description + illustration

Rural Zambia

1. FTFI: No description

2. FTFI: Detailed description

3. FTFI: Detailed description + illustration

Male circumcision was described to the participant before asking about his/her partner's circumcision status, except in the control arm of the experiment in rural Zambia, where the participant was asked about circumcision status without any preceding description. The descriptions were either given along with an illustration or alone. In Lusaka, a simple description was provided, "Male circumcision is when the foreskin of the penis is removed or cut off." In Swaziland and rural Zambia, the description was more detailed, "Male circumcision is the removal of the foreskin from the head of the penis. The foreskin is the skin that covers all or most of the head of the penis of uncircumcised men. You can see if a man is circumcised by looking at his penis when he does not have an erection. When men are circumcised, you can see the head of the penis. When they are uncircumcised, the head may be partially or completely hidden by the foreskin. When the penis of an uncircumcised man is erect (hard), usually the foreskin pulls back and the head of the penis is uncovered." The illustration was changed in the latter two sites because feedback from the Lusaka site/phase suggested that the drawing was insufficiently clear.

All male participants were subsequently asked, "Are you circumcised?" while female participants were asked, "Is the man you came to the clinic with circumcised?" To verify the reported

${ }^{1}$ At all sites, efforts were made to verify that the couples participating in the study were actually sexual partners by asking (separately) each adult male participant and his female partner a series of questions about their partner. 
circumcision status of participants, male participants were asked to undergo a visual examination conducted by a trained clinician. To avoid the possibility that prior knowledge of the clinical examination might affect the participant's reporting of his MC status, informed consent for the physical examination was requested separately and only after the survey interview was completed.

\section{Results}

In urban Zambia and Swaziland, similar percentages of men were determined by physical examination to be circumcised (16 and 17 percent of the male sample respectively). Seventy-nine percent of those circumcisions were reported by the participant to be medical circumcisions, while 21 percent were reported to be traditional MCs. In rural Zambia, approximately 7 percent of the sample were found by the clinician to be fully circumcised, and an additional 5 percent partially circumcised.

Levels of misreporting of MC status show similar patterns across sites. In urban Zambia, adult males misreport their MC status at relatively low levels (3 percent on average). Misreporting of MC status is significantly higher among adolescents $(7$ percent, $\mathrm{p}<.05)$ and female partners (11 percent, $\mathrm{p}<.01)$; female partners are also significantly more likely to indicate that they do not know their partner's status ( 8 percent, $\mathrm{p}<.01)$. In urban Swaziland, the proportion misreporting among adolescents and adult men is the same ( 6 percent), with female partners misreporting at two and a half times the level of males $(15$ percent, $\mathrm{p}<.01)$. The patterns of misreporting for rural Zambia are similar to those for urban Zambia and Swaziland, with significant differences observed by sex $(6$ percent males versus 12 percent females, $\mathrm{p}<.01)$.

For males the bias in reporting of MC status is largely unidirectional, with uncircumcised men reporting that they are circumcised; few circumcised men misrepresent their MC status. Among females, there is a bias in reporting in both directions-i.e., some women with circumcised partners report that their partner is uncircumcised, and some women with uncircumcised partners report that they are circumcised.

Contrary to expectations, misreporting tended to be higher with ACASI than in the FTFI method for both descriptive and multivariate analysis. The general pattern of consistently higher misreporting of MC status in ACASI suggests that the privacy and confidentiality afforded by computerized interviewing does not improve, and potentially compromises, the accuracy of reported MC status. Given the poor performance of ACASI in Swaziland and Lusaka, it was not further evaluated in rural Zambia.

Although the experimental arms did not initially reveal improvement in the reporting of MC status, investigators assessed whether an illustration of a circumcised and uncircumcised penis reduced misreporting, particularly for participants who were not able to read a simple sentence. To assess this question, the data were pooled across all sites and unadjusted and adjusted regression models were estimated. In the unadjusted model, the odds ratio (OR) for the illustration group is not significant and reveals no differences relative to the reference group. For the adjusted odds ratio (AOR), however, the results become statistically significant. For illiterate participants, the illustration reduces the odds of misreporting by 34 percent in the OR and by 38 percent in the AOR models. The effect of the illustration by literacy status is confirmed in a model that included an interaction term for illiteracy and provided an illustration $(\mathrm{p}<.01)$. 


\section{Conclusions and Recommendations}

Between 3 and 7 percent of males in the study misreported their circumcision status when compared with results of a clinical exam. These results suggest that the prevalence of MC may be overestimated by approximately 4 percent in Zambia and 5 percent in Swaziland. This represents a significant fraction of the $\mathrm{MC}$ prevalence currently reported in both countries: 13 percent reported as circumcised in Zambia (CSO 2010) and 8 percent in Swaziland (CSO 2008). In addition, estimates of the influence of MC on HIV incidence are likely to be attenuated given over reporting of MC status. These results indicate that inaccurate self-reports of MC status are a concern in Zambia and Swaziland, which parallels findings from other countries (e.g., Weiss et al. 2008; Urassa et al. 1997; Risser et al. 2004; Schlossberger et al. 1991; Thomas et al. 2010).

Between 11 and 15 percent of women did not accurately report the circumcision status of their partners, with the bias in reporting in both directions. Clinical trials testing potential HIV prevention technologies and behavioral interventions rely alike on women's reports of their partner's MC status to control for confounding effects of MC in analyses of secondary endpoints. The accurate measurement of other HIV risk and protective factors in observational studies with women participants will also be undermined if inaccurate partner reports of circumcision status are trusted.

To improve reporting, this study sought to address lack of knowledge through instruction (via both a simple and a more specific verbal description of circumcision, as well as an illustration of a circumcised and an uncircumcised penis), and sought to address social desirability bias through the use of ACASI. It also sought to assess the acceptability of physical examination by a trained clinical officer to determine MC status. The study found that it is feasible and acceptable to use a detailed description and/or illustration of $\mathrm{MC}$ with little negative feedback from the population. It also found, however, that physical examinations in some settings are not acceptable (30 percent of males in Lusaka refused to participate in the examination).

The results indicated that ACASI does not improve, and likely compromises the accuracy of reported MC status. The poor performance of ACASI suggests that participants may have felt a greater obligation to respond honestly to an interviewer, implying that social desirability bias is probably not a factor in misreporting MC in these settings. It should be noted, however, that social desirability bias may become more of an issue as $\mathrm{MC}$ programs are scaled-up, mass media messaging becomes pervasive, and circumcision becomes more normative. It is also possible that in the event of uncertainty, face-to-face interviews provided a greater opportunity for the interviewer and participant to discuss the nature of circumcision; interviewers were not prohibited from assisting participants if the participant asked for additional clarification or explanation.

The study found that providing an illustration for illiterate participants improves reporting of MC status: misreporting among illiterate participants declined from 13 percent without an illustration to 10 percent when one was provided. Unexpectedly, the results indicate that misreporting was more common among literate participants when they were given an illustration; however, the regression results indicate that the findings were not as substantial as the reduction in misreporting for illiterate participants. Moreover, this anomaly disappears when the Lusaka data - where a less clear illustration was used - are dropped from the model. The overall conclusion drawn is that illustrations are a useful method for improving the reporting of MC status for both males and females. 
These findings echo those from other studies that suggest misreporting of MC status is a concern for researchers and program managers interested in measuring the prevalence of $\mathrm{MC}$ or using MC status as an indicator in models of HIV/STI outcomes. It is the first study to our knowledge that has looked at female misreporting of partner MC status. The study suggests that errors in reporting occur for both males and females and have the potential to skew prevalence studies and to mask positive effects of prevention interventions. To compensate, providing an illustration along with a detailed description of MC may help improve self- and partner reporting of MC, particularly among illiterate populations. 


\section{INTRODUCTION}

\section{The Male Circumcision Partnership}

Randomized controlled trials have shown that male circumcision reduces the risk of HIV infection among heterosexual men by about 60 percent (Auvert et al. 2005; Bailey et al. 2007; Gray et al. 2007). Modeling predicts that large-scale male circumcision provision in sub-Saharan Africa could avert approximately 2 million new infections in ten years and an additional 3.7 million infections in the following decade (Williams et al. 2006). The largest impact is projected for southern Africa, where HIV prevalence is high and male circumcision is low. Based on these findings, a WHO/UNAIDS Technical Consultation recommended that male circumcision be implemented in areas with a high prevalence of HIV infection (WHO/UNAIDS 2007).

At the time of this report, Population Services International and its partners Marie Stopes International, Jhpiego, and the Population Council—together the Male Circumcision Partnership-are working with the Ministry of Health $(\mathrm{MOH})$ to expand access to high-quality male circumcision (MC) services in Zambia. At the initiation and completion of fieldwork, the Partnership was also active in Swaziland. MC prevalence (medical and traditional) is still low in both countries, approximately 13 percent in Zambia (CSO 2010) and 8 percent in Swaziland (CSO 2008), with considerable variation across provinces in Zambia due to regional differences in the practice of traditional MC (Buckner et al. 2006). Within five years (2009-2013) the MC Partnership aims to circumcise approximately 490,000 men in Zambia with the goal of raising the prevalence of $\mathrm{MC}$ to 32 percent. The target age range for circumcision is 13-29, although no males will be denied the service. The MC Partnership aims to increase demand for MC services through social marketing and behavior change communication campaigns, while keeping in mind cultural and traditional factors that are closely related to ethnic identity.

The MC Partnership program supports the Zambian MOH's proportion of HIV prevention activities and the scale-up of MC services nationally. In late 2009, the Zambian National Male Circumcision Strategy and Implementation Plan 2010-2020 was adopted by the MOH. The goal of the plan is to "make high-quality, safe male circumcision services accessible and available to all men and boys on a voluntary basis" (MOH 2010). The specific objectives are to increase the number of sites providing male circumcision services and increase the number of HIV-negative males, including neonates, who become circumcised. The Zambian Ministry of Health's target is to reach an adult male circumcision prevalence of 50 percent and a neonatal prevalence of 80 percent by 2020 (MOH 2010).

The MC Partnership recognizes the need for research and evaluation to measure uptake in MC services and ensure that high-quality service is maintained as the number of MC providers and sites expands. The Population Council is conducting research and evaluation on key issues during implementation to improve the efficiency, cost-effectiveness, and quality of MC services.

The study described in this report aims to assess the validity of self- and partner reports of male circumcision status and to assess whether a visual aid depicting a circumcised penis and an uncircumcised penis improves the accuracy of reporting compared with a verbal description of circumcision. Results of the study will inform cross-sectional and longitudinal behavioral surveys to be implemented by the MC Partnership. The study will also provide information regarding the accuracy of self-reported circumcision status to the HIV prevention field, which is increasingly considering MC status in its program design and research. 


\section{Background}

Accurate measurement of MC status is critical to cross-sectional and longitudinal studies that seek to assess HIV risk. Given the logistical constraints, and the resources required to perform physical examinations to ascertain circumcision status, particularly in household-based surveys, the quality of data obtained from self- and partner reports of MC status must be assessed.

Discrepancies between self-reports and actual circumcision status may be a function of: 1) lack of knowledge-i.e., a poor understanding of what is meant by circumcision, 2) reporting biases due to social norms regarding circumcision, and 3) physical differences-i.e., variations in the length of the foreskin or in the completeness of circumcision. Moreover, given the potential impact of $\mathrm{MC}$ on females' HIV risk and that women are asked to report on the circumcision status of their partner in HIV prevention trials, it is also critical to assess women's ability to accurately identify their partner's circumcision status.

Of those studies that have been conducted, a few have found accurate reporting of circumcision status when reporting was confirmed by clinical examination. For instance, Castellsagué and colleagues (2002) pooled data from case-control studies in five countries (Brazil, Thailand, the Philippines, Spain, and Colombia) examining the link between MC and HPV and found that self-reported circumcision was accurately reported by 95 percent of the male participants. Further, in a prospective cohort study of truckers in Kenya, only 1 out of 746 men failed to report circumcision status accurately (Lavreys et al. 1999); in this population, however, prevalence of MC was almost 90 percent. In the Castellsagué analysis, overall prevalence of MC was low in the study countries and no African country was included.

More recently, Westercamp and colleagues conducted a population-based survey in Kisumu, Kenya and found that among the 37 percent of participants who consented to a visual genital exam, 7 percent who reported they were circumcised were not actually circumcised (Westercamp et al. 2010). While the authors conclude that in this population, self-reports had strong agreement with a clinical exam, 7 percent is not negligible, and it may be that the results would differ had the other two-thirds of the sample agreed to a visual exam and their report of MC status been confirmed.

Similarly, a number of studies have found substantial discrepancies between self-reports of MC and clinical assessment. A study in Mwanza, Tanzania, which validated self-reports with clinical observation, found that 82 percent of adolescent males who reported being circumcised had actually been circumcised (Weiss et al. 2008). The study population had a low level of circumcision (12 percent). An earlier study in Mwanza found that only 69 percent of men reporting $\mathrm{MC}$ were found to be circumcised (fully or partially) upon clinical examination (Urassa et al. 1997). Risser and colleagues (2004) examined whether adolescent males in Houston, Texas could correctly report their circumcision status. Investigators found that agreement between the clinician and participant was 67 percent, largely because many adolescents were unsure of their status. Another study in the U.S. among 11 to 14 year-olds found that self-reports were only accurate among 68 percent of participants (Schlossberger et al. 1991). An unpublished analysis, conducted at the Orange Farm site in South Africa, reports that almost half ( 45 percent) of the men who reported they were circumcised were found to have an intact foreskin upon physical examination; in contrast, 99.6 percent of men who reported they were not circumcised reported accurately when compared to the clinician's assessment (unpublished, Bophelo Pele website accessed March 2011). A study among male defense force applicants in Lesotho found a similarly high rate of misreporting — only 50 percent of participants who reported being circumcised had a full circumcision upon clinical exam (Thomas et al. 2010). 
Variation in the type or completeness of circumcision and in the natural foreskin length may contribute to misclassification of circumcision status (Weiss et al. 2008). To the best of our knowledge, few studies have assessed these variations. Brown and colleagues (2001) found three general types of circumcision in a region of Kenya, with variability in the parts and amounts of foreskin that had been removed among circumcised men. Agreement between men's self-reports and clinicians' observations was 81 percent. Urassa and colleagues (1997) identified 8 out of 202 factory workers to be partially circumcised-all of whom reported that they were circumcised. The Kenyan study among truckers excluded six men from the analysis who were partially circumcised (Lavreys et al. 1999). The population-based study in Kisumu found that among the participants who consented to an exam, 9 (3 percent) were partially or "abnormally" circumcised (Westercamp et al. 2010). The study by Thomas and colleagues in Lesotho found that among the participants who reported that they were circumcised, 27 percent had partial circumcision as determined by a physician (Thomas et al. 2010). In the study among adolescents in Texas, researchers found that 1.2 percent of participants were partially circumcised (Risser et al. 2004).

Finally, to our knowledge, there have been no quantitative studies assessing the accuracy of females' reports of partner circumcision status. A study in Tanzania that included qualitative interviews with adolescent girls found that the majority did not know what $\mathrm{MC}$ was (Weiss et al. 2008). Moreover, a clinical study of a microbicide placebo that investigated variance in adherence reporting by interview method in South Africa found that women in a face-to-face interview were significantly less likely than those interviewed with ACASI to report "don't know" when asked about circumcision status of their partners ( 8 percent versus 19 percent). This finding suggests that women may be unwilling to acknowledge that they don't know what is meant by $\mathrm{MC}$ when asked by an interviewer and thus may misreport partner's MC status in face-to-face interviews (Mensch et al. 2009).

To improve the accuracy of reporting, researchers need to identify and address the underlying reasons for misreporting, such as lack of knowledge, reporting bias, or physical differences. To compensate for inadequate knowledge, researchers have recommended testing visual aids (Weiss et al. 2008). Indeed, one study among boys aged 11-14 in the U.S. found the use of visual aids substantially increased the accuracy of reporting (from 68 percent to 92 percent; Schlossberger et al. 1991). In contrast, Risser et al. (2004) found that among boys who did not know their status and then were shown a picture, many still could not correctly identify their status.

Another potential remedy for lack of understanding of circumcision is to define MC for participants. Surveys typically ask only whether the participant is circumcised. For example, the most recent Zambia and Swaziland DHS asked, "Some men are circumcised. Are you circumcised?" (CSO [Zambia] 2009, p. 478; CSO [Swaziland] 2008, p. 456); the Zambian Sexual Behavior Survey asks, "Some men or women have been circumcised. Have you been circumcised?” (CSO 2010, p. B33).

The second possible cause of inaccurate reporting cited above—social desirability bias—can also be addressed. Studies in the U.S. and elsewhere have indicated that the use of computerized selfinterviews can significantly reduce such biases in surveys (Booth-Keweley et al. 2007; Hewett et al. 2008; Mensch et al. 2008; Tourangeau et al. 2000; Wilkerson et al. 2002).

The literature thus suggests that there are varying degrees of misreporting of circumcision status by men and likely by their female partners as well. Our study was designed to assess the degree to which males and females accurately report their own or their partner's MC status, what underlies people's misreporting, and how accuracy of reporting might be improved. We focused on two of 
the possible reasons for misreporting: lack of understanding (knowledge) and social desirability (reporting biases). The third factor, variation in completeness of circumcision or foreskin length, was assessed, but no additional intervention was tested to improve inaccurate reporting due to this factor.

\section{Study Objectives}

The ultimate objective of this study is to provide HIV/AIDS researchers with evidence-based recommendations for the collection of self-reported data on MC status through an assessment of different methods aimed at improving the accuracy of self-reports.

\section{Specific objectives}

1. Assess the acceptability of verbal descriptions and illustrations for use in surveys about circumcision status.

2. Assess the accuracy of MC status reporting when a printed illustration is shown to the participant in a face-to-face interview compared to clinical assessment.

3. Assess the accuracy of MC status reporting after a computer graphic illustration is shown on an ACASI screen compared to clinical assessment.

4. Compare the accuracy of MC status reporting when illustrations are used in conjunction with a verbal description compared to when a verbal description alone is provided (either simple or detailed).

5. Compare the percent of participants responding "don't know" to a question about MC status when illustrations are used versus when a verbal description of $\mathrm{MC}$ is provided.

6. Determine whether the reporting of MC status varies according to type (traditional versus medical) and completeness of circumcision. 


\section{METHODS}

\section{Ethical Considerations}

The study protocol, informed consent forms, and study instruments were reviewed and approved by the Institutional Review Board (IRB) of the Population Council and by the University of Zambia (UNZA) Research Ethics Committee. A synopsis of the study and the study final report were submitted for review to the Zambian $\mathrm{MOH}$.

Written informed consent was obtained from adult participants and from parents and guardians of minors participating in the study. Assent was obtained from minors after informed consent was provided by parents and guardians. Clients of health centers were assured that if they did not wish to participate in the study, their health care would not be affected. Interviews and physical examinations were conducted in a private setting. All personal identifying information was removed from the data collected and kept in a secure location where only authorized personnel had access.

\section{Sample}

The study was conducted sequentially in three sites/phases, first in urban Zambia (Lusaka) from July 2009 through September 2009, second in urban Swaziland (Mbabane and Matsapha) from November 2009 through February 2010, and finally in rural Zambia (selected wards within 20 kilometers of Lusaka) from April 2010 to May 2010.

Men aged 18-50 and their female partners, as well as adolescent boys aged 13-17, were eligible for the study. Study participants were recruited from clients visiting HIV counseling and testing (CT) sites and health centers and from the communities surrounding the facilities. Clinic facilities that offered MC services were specifically avoided. In urban areas of Zambia and Swaziland, announcements inviting participation in the study were posted at numerous locations around town. Additional outreach was conducted by a mobile coordinator who introduced the study to adult and adolescent male support and sports groups. In rural Zambia, outreach was conducted by village headmen and community outreach workers who recruited couples from their communities.

During study recruitment, outreach staff indicated only that a study was seeking volunteers for an HIV prevention study and made no reference to male circumcision or the specific purposes of the study so as not to influence potential participants. At all sites, efforts were made to verify that the couples participating in the study were actually sexual partners. Each adult male participant and his female partner were interviewed separately and asked a series of questions about his circumcision status, among other topics. Interviews were conducted in English and local languages-SiSwati in Swaziland and English, Nyanja, and Bemba in Zambia. Depending on the method of recruitment and distance traveled, participants were reimbursed for transportation to the study site and/or for their participation time. 


\section{Study Design}

The study design varied by site/phase, with preliminary results from each site/phase informing the next stage of data collection. At all phases, participants were randomized to one of three experimental arms. An outline of the study design implemented for each site is presented in Box 1. In urban Zambia all participants were given a simple description of circumcision: "Male circumcision is when the foreskin of the penis is removed or cut off." For two of the study arms, an illustration was also shown to the participant and the differences between the circumcised and uncircumcised penis noted. Male participants were subsequently asked, "Are you circumcised?" while female participants were asked, "Is the man you came to the clinic with circumcised?" For two of the arms in urban Zambia, the question was presented in a face-to-face interview (FTFI), while in one arm the question was asked via an audio computer-assisted self-interview (ACASI) (see Appendix B for description of ACASI). 


\section{Study arms for each site}

\section{Urban Zambia (Lusaka)}

FTFI: Simple description

FTFI: Simple description + illustration

ACASI: Simple description + illustration

\section{Rural Zambia}

FTFI: No description

FTFI: Detailed description

FTFI: Detailed description + illustration

\section{Urban Swaziland (Mbabane and Matsapha)}

FTFI: Detailed description

FTFI: Detailed description + illustration

ACASI: Detailed description + illustration

\section{Descriptions}

Simple: "Male circumcision is when the foreskin of the penis is removed or cut off."

Detailed: "Male circumcision is the removal of the foreskin from the head of the penis. The foreskin is the skin that covers all or most of the head of the penis of uncircumcised men. You can see if a man is circumcised by looking at his penis when he does not have an erection. When men are circumcised you can see the head of the penis. When they are uncircumcised the head may be partially or completely hidden by the foreskin. When the penis of an uncircumcised man is erect (hard), usually the foreskin pulls back and the head of the penis is uncovered."

\section{Illustrations}

\section{Used in Lusaka}

Circumcised penis

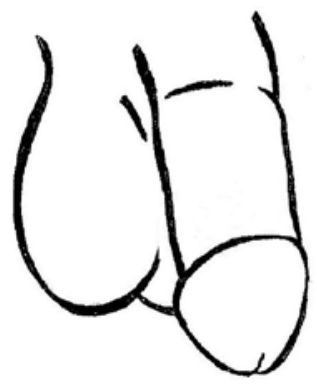

Used in Swaziland and rural Zambia

\section{Circumcised penis}

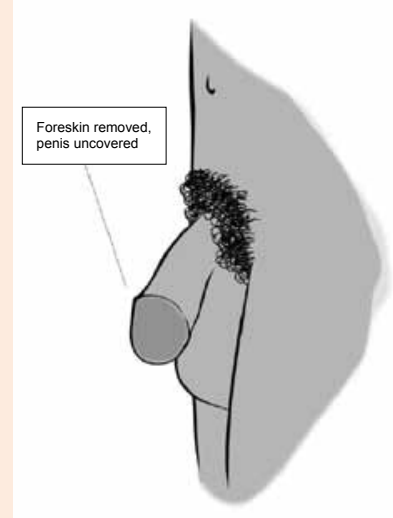

Circumcised flaccid penis
Uncircumcised penis

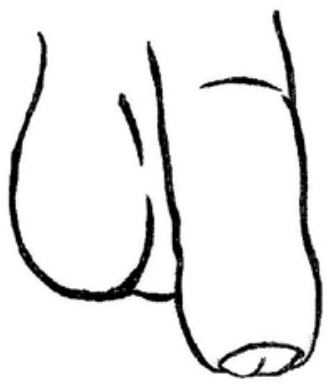

Uncircumcised penis

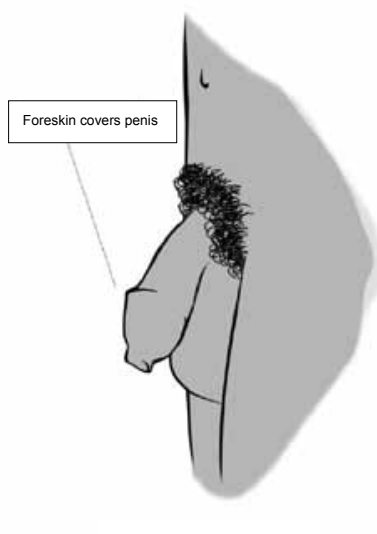


For Swaziland and rural Zambia, two adjustments were made in the implementation of the study as a result of the Lusaka findings. The simple description of circumcision was replaced with a more detailed description (see Box 1) to determine whether providing more verbal information about MC would be as effective as the illustration. If a detailed description were sufficient, it would eliminate the need for the interviewer to show the illustration, eliminating the possibility of any potential negative reaction occasioned by the graphic nature of the picture. Further, the illustration was changed because of a concern that the original image of the uncircumcised penis was not sufficiently clear. The updated illustration used in urban Swaziland and rural Zambia was obtained from the MC Partnership counseling and training materials.

Additional details of the study design were changed in rural Zambia in response to findings from urban Zambia and Swaziland. The computerized interview was eliminated, since it did not perform better than the other methods in obtaining accurate reports of MC status in the prior sites. Further, the adolescent sample was dropped because sufficient differences were not observed in urban Zambia or Swaziland to justify separate data collection for this age group. Finally, the control arm provided no description or illustration of circumcision and straightforwardly asked: "Now we would like to ask, are you circumcised?" The approach used was to determine the potential magnitude of MC status misreporting in surveys that provided neither a description nor an illustration to assist the participant (ZDHS, ZSBS).

To verify the reported circumcision status of participants, male participants were asked to undergo a visual examination conducted by a trained clinician. If the clinician observed symptoms of a sexually transmitted infection, the participant was referred for treatment. To avoid the possibility that prior knowledge of the clinical examination might affect participants' reporting of their MC status, informed consent for the physical examination was requested separately and only after the survey interview was completed.

Samples sizes were set to detect a 15 percent difference (effect size) between the control and experimental arms in the percent misreporting their circumcision status or answering don't know, with a power of .80 and alpha of .05 . The sample size calculation is based on a one-sided statistical test since it was assumed that the visual aid would produce better reporting than the verbal description. However, given the small differences between experimental arms observed in the study, these sample sizes were not sufficient to detect differences statistically. 


\section{RESULTS}

The distribution of study participants by arm in each of the sites/phases of the study is shown in Table 1. Block randomization methods were used to assure equivalence across study arms. However, the analytic sample varies by arm as a result of missing data.

Table 1. Distribution of study participants by study arms

\begin{tabular}{l|c|c|c|} 
& & \multicolumn{2}{|c}{ Couples } \\
& Males 13-17 & Males 18-50 & Females 18-50 \\
Urban Zambia & & & 147 \\
FTFI SD & 145 & 147 & 146 \\
FTFI SD + illustration & 154 & 146 & 127 \\
ACASI SD + illustration & 139 & 127 & 420 \\
Total interviewed & 438 & 420 & 135 \\
Urban Swaziland & & & 133 \\
FTFI DD & 133 & 135 & 133 \\
FTFI DD + illustration & 136 & 133 & 401 \\
ACASI DD + illustration & 133 & 433 & 149 \\
Total interviewed & 402 & 149 & 147 \\
Rural Zambia & & 147 & 147 \\
FTFI no description & - & 147 & 443 \\
FTFI DD & - & 443 & \\
FTFI DD + illustration & - & - &
\end{tabular}

Notes: FTFI = Face-to-face interview; $\mathbf{S D}=$ simple description, $\mathbf{A C A S I}=$ Audio computer-assisted self-interview, $\mathbf{D D}=$ detailed description.

Instruments were translated into SiSwati in Swaziland and Nyanja and Bemba in Zambia.

A number of electronic cases were lost in the ACASI data from Lusaka.

\section{Participant Characteristics}

The characteristics of the participants by study site are indicted in Table 2. The mean age of the adolescent sample was 15.1 years in Lusaka and 16.1 years in Swaziland. For adult men, the mean ages were 34.6, 29.7, and 39.9 in urban Lusaka, urban Swaziland, and rural Zambia, respectively. The mean ages for women were 29.1, 25.4, and 33.2. A somewhat older sample of couples was obtained in Zambia than in Swaziland. As expected, the adult sample was slightly more educated than the adolescent sample, as a number of young men were still attending school and had not completed their education. Males had higher levels of education than females in Zambia, with greater educational parity by sex in Swaziland. As expected, given the median age of marriage for men in Zambia and Swaziland, almost all adolescent males were unmarried. In both urban Zambia and Swaziland, more than half of the couples were in formal unions; a substantial percentage of discordant reporting between males and females regarding marital status was observed in Swaziland. Tribal affiliation varied in Zambia, reflecting the diversity within the country. Almost all participants indicated their religious affiliation as Christian in both countries. 
Table 2. Demographic characteristics of study participants (percentages unless otherwise indicated)

\begin{tabular}{|c|c|c|c|c|c|c|c|c|c|}
\hline \multirow[b]{2}{*}{ Characteristic } & \multicolumn{3}{|c|}{ Urban Zambia } & \multicolumn{3}{|c|}{ Urban Swaziland } & \multicolumn{3}{|c|}{ Rural Zambia } \\
\hline & $\begin{array}{l}\text { Males } \\
13-17 \\
N=438\end{array}$ & $\begin{array}{l}\text { Males } \\
18-50 \\
\mathrm{~N}=420\end{array}$ & $\begin{array}{c}\text { Females } \\
18-50 \\
N=420\end{array}$ & $\begin{array}{l}\text { Males } \\
13-17 \\
\mathrm{~N}=402\end{array}$ & $\begin{array}{l}\text { Males } \\
18-50 \\
N=401\end{array}$ & $\begin{array}{c}\text { Females } \\
18-50 \\
N=401\end{array}$ & $\begin{array}{l}\text { Males } \\
13-17\end{array}$ & $\begin{array}{l}\text { Males } \\
18-50 \\
N=443\end{array}$ & $\begin{array}{c}\text { Females } \\
18-50 \\
N=443\end{array}$ \\
\hline Mean age in years & 15.1 & 34.6 & 29.1 & 16.1 & 29.7 & 25.4 & - & 39.9 & 33.2 \\
\hline $\begin{array}{l}\text { Highest level } \\
\text { education } \\
\text { completed }\end{array}$ & & & & & & & & & \\
\hline None & 3 & 2 & 5 & 2 & 2 & 1 & - & 3 & 11 \\
\hline Some primary & 27 & 7 & 15 & 15 & 7 & 8 & - & 13 & 26 \\
\hline $\begin{array}{l}\text { Completed } \\
\text { primary }\end{array}$ & 20 & 12 & 19 & 13 & 4 & 7 & - & 24 & 24 \\
\hline Some secondary & 45 & 31 & 33 & 57 & 27 & 34 & - & 41 & 35 \\
\hline $\begin{array}{l}\text { Completed } \\
\text { secondary }\end{array}$ & 3 & 21 & 12 & 10 & 32 & 26 & - & 7 & 3 \\
\hline Higher & 2 & 27 & 16 & 3 & 29 & 25 & - & 12 & 1 \\
\hline Marital status & & & & & & & & & \\
\hline Never married & 97 & 17 & 15 & 99 & 37 & 49 & - & 0 & 0.5 \\
\hline $\begin{array}{l}\text { Currently married } \\
\text { or living together }\end{array}$ & 3 & 81 & 82 & 1 & 62 & 51 & - & 100 & 99 \\
\hline $\begin{array}{l}\text { Separated, } \\
\text { divorced, } \\
\text { widowed, other }\end{array}$ & 0 & 3 & 3 & 0 & 1 & 0 & - & 0 & 0.5 \\
\hline Tribe & & & & & & & & & \\
\hline Lozi & 7 & 7 & 8 & - & - & - & - & 5 & 4 \\
\hline Ngoni & 11 & 8 & 8 & - & - & - & - & 9 & 5 \\
\hline Tonga & 11 & 10 & 11 & - & - & - & - & 35 & 26 \\
\hline Lunda & 4 & 4 & 3 & - & - & - & - & 1 & 1 \\
\hline Bemba & 25 & 29 & 29 & - & - & - & - & 12 & 8 \\
\hline Kaonde & 3 & 3 & 3 & - & - & - & - & 1 & 2 \\
\hline Luvale & 1 & 2 & 1 & - & - & - & - & 1 & 0 \\
\hline Swazi & - & - & - & 100 & 98 & 98 & - & - & - \\
\hline Other & 38 & 37 & 37 & 0 & 2 & 2 & - & 36 & 54 \\
\hline Religion & & & & & & & & & \\
\hline Christian & 99 & 97 & 99 & 95 & 95 & 99 & - & 100 & 100 \\
\hline Other & 1 & 3 & 1 & 5 & 5 & 1 & - & 0 & 0 \\
\hline $\begin{array}{l}\text { Literacy test } \\
\text { results }\end{array}$ & & & & & & & & & \\
\hline Cannot read & 13 & 6 & 19 & 4 & 4 & 2 & - & 16 & 32 \\
\hline $\begin{array}{l}\text { Able to read only } \\
\text { part of sentence }\end{array}$ & 16 & 5 & 14 & 1 & 1 & 3 & - & 7 & 15 \\
\hline $\begin{array}{l}\text { Able to read whole } \\
\text { sentence }\end{array}$ & 71 & 89 & 67 & 94 & 95 & 95 & - & 77 & 53 \\
\hline
\end{tabular}

Note: Sample sizes for individual characteristics may vary because of missing values. 


\section{Numeracy and Literacy Assessment}

Study participants were also asked to complete an assessment of number recognition and basic literacy (see Appendix C). In addition to identifying skills acquired as part of their education, these assessments were useful for evaluating whether participants had sufficient numeric ability to complete the self-administered computerized questionnaire (see Appendix B for a description of ACASI). In the numeracy assessment, participants were asked to identify numbers that were randomly ordered on a card from 1 to 10 . For the literacy evaluation, participants were asked to read a simple sentence and their ability to read all, part, or none of the sentence was recorded. In Zambia, participants were asked to read a sentence in English, while in Swaziland most participants were asked to read a sentence in SiSwati, the local language.

As can be observed in Figure 1a, although number recognition is nearly universal in both urban Zambia and Swaziland (between 98 and 99 percent), approximately 7 to 8 percent of participants in rural Zambia were not successful in identifying numbers. In the two Zambian sites, the ability to read a simple English sentence is not universal; between 71 percent and 89 percent of males and between 50 percent and 65 percent of females were able to successfully complete the literacy assessment (see Table 2 and Figure 1b). In Swaziland, the ability to read a simple sentence was nearly universal among both males and females, due, perhaps, to the fact that most participants were tested in the local language.

\section{Figure 1a. Percent demonstrating numeracy}

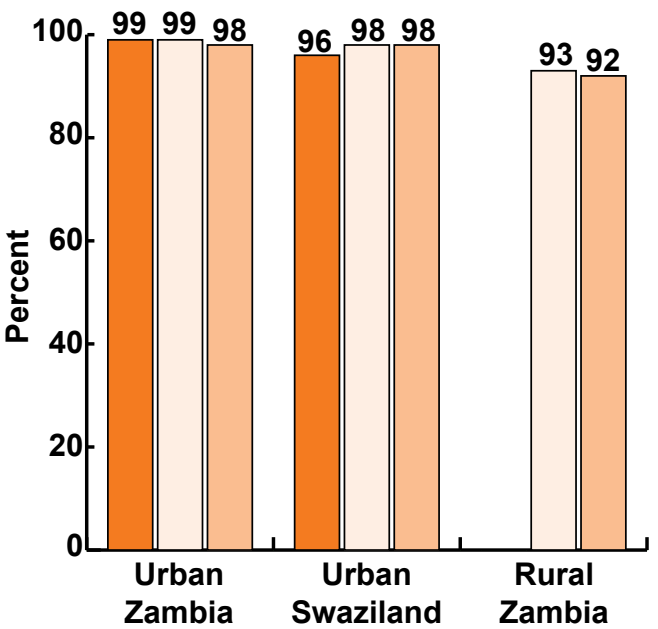

Figure 1b. Percent able to read simple sentence

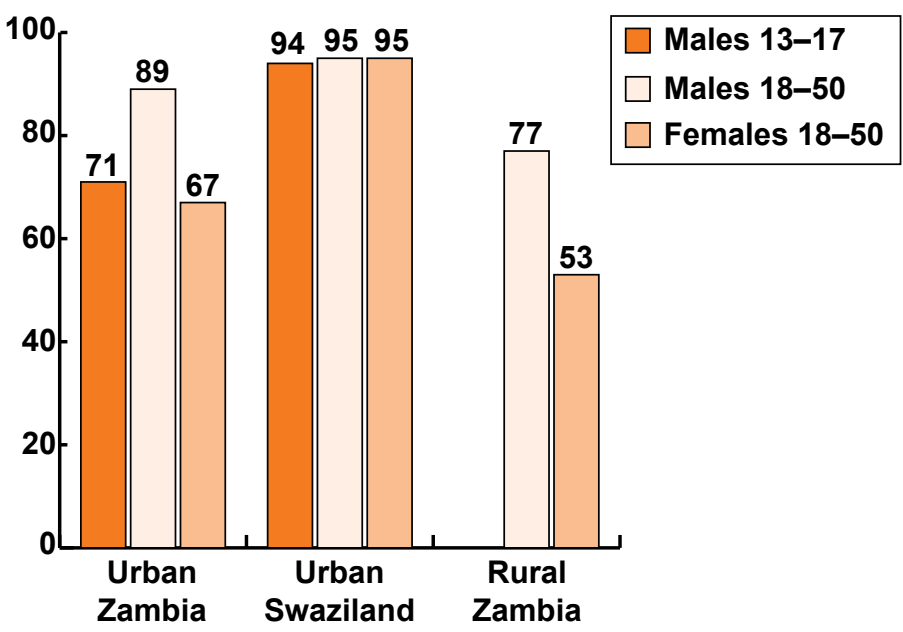

A specific objective of this study was to assess the acceptability of using a verbal description of circumcision and an illustration of a circumcised and an uncircumcised penis to assist in the identification of circumcision status. Given the explicit nature of the description and illustration, there was a concern that study participants might be offended by this part of the interview and refuse to continue. However, those fears appeared to be unfounded as there was no indication that either the description or illustration elicited any significant negative reaction from participants. A caveat is that the study was conducted in HIV testing and health clinics and therefore the level of acceptance was perhaps greater than might be expected in a household study. 


\section{Knowledge of Male Circumcision and HIV}

Table 3 shows the percent of participants who had heard of male circumcision prior to its being described to them, as well as the percent of the sample who had comprehensive knowledge about HIV and AIDS. Knowledge of male circumcision is reported to be quite high for the male and female adult samples, although much lower in Lusaka among adolescents (73 percent) and females ( 82 percent). The knowledge of $\mathrm{MC}$ is likely high because of the prominence of traditional MC among some tribes, as well as exposure to media/promotional messages on MC. For example, the proportion of participants who reported having seen an advertisement related to MC was 72 percent, 82 percent, and 74 percent for adolescent males, adult males, and females, respectively (for all sites combined, data not show).

Table 3. Knowledge of male circumcision and HIV (percentages)

\begin{tabular}{l|c|c|c|} 
& $\begin{array}{c}\text { Males } \\
\text { Heard of MC prior to interview }\end{array}$ & $\begin{array}{c}\text { Males } \\
18-17\end{array}$ & $\begin{array}{c}\text { Females } \\
18-50\end{array}$ \\
$\quad$ Urban Zambia & 73 & 90 & 82 \\
Urban Swaziland & 93 & 96 & 93 \\
$\quad$ Rural Zambia & - & 90 & 88 \\
Comprehensive knowledge about HIV and AIDS ${ }^{\dagger}$ & & & \\
$\quad$ Urban Zambia & 73 & 94 & 89 \\
$\quad$ Urban Swaziland & 66 & 76 & 77 \\
Rural Zambia & - & 82 & 67 \\
\hline
\end{tabular}

†Defined as answering correctly that reducing partners, using condoms, and abstinence are HIV prevention methods; that one cannot become infected by sharing food with someone who has AIDS; and that it is possible for a person who looks healthy to have AIDS.

\section{Physical Examination Refusals}

As seen in Table 4, approximately 30 percent of males declined the physical examination in Lusaka, whereas a much smaller percentage refused in Swaziland. Refusal rates in Lusaka were unrelated to interview mode or to most demographic characteristics, although participants with a secondary or higher education were more likely to refuse the exam, while participants from the Lozi and Lunda tribes were marginally less likely to refuse. In Swaziland, participants who were not able to read English were significantly more likely to refuse an examination $(\mathrm{p}<.001$, data not shown).

Table 4. Physical examination refusals

\begin{tabular}{l|c|c|c|c|c|c|} 
& \multicolumn{3}{|c|}{ Males 13-17 } & \multicolumn{3}{c}{ Males 18-50 } \\
& Interviewed & Examined & $\begin{array}{c}\text { Refused } \\
\text { exam }\end{array}$ & Interviewed & Examined & $\begin{array}{c}\text { Refused } \\
\text { exam }\end{array}$ \\
Urban Zambia & 438 & 311 & $29 \%$ & 420 & 318 & $24 \%$ \\
Urban Swaziland & 402 & 381 & $5 \%$ & 401 & 371 & $8 \%$ \\
Rural Zambia & - & - & - & 443 & 439 & $1 \%$ \\
\hline
\end{tabular}




\section{Circumcision Status of Participants}

Figure 2 indicates the percentage of men who were circumcised according to physical examination. The levels of circumcision in urban Zambia and Swaziland are similar, with 16 and 17 percent of the sample circumcised. These proportions are higher than national averages, likely because the men were sampled from urban areas where MC services were more widely available at the time of the study. Of those men who were circumcised, 79 percent reported they had medical circumcisions, while 21 percent reported traditional circumcisions. In rural Zambia, approximately 7 percent of the sample was classified by the clinician as having full circumcisions, and an additional 5 percent as partial. The relatively higher percentage of partial circumcisions found in rural Zambia is further evaluated below in the discussion of participant reporting.

Figure 2. Circumcision status of male sample according to clinician assessment

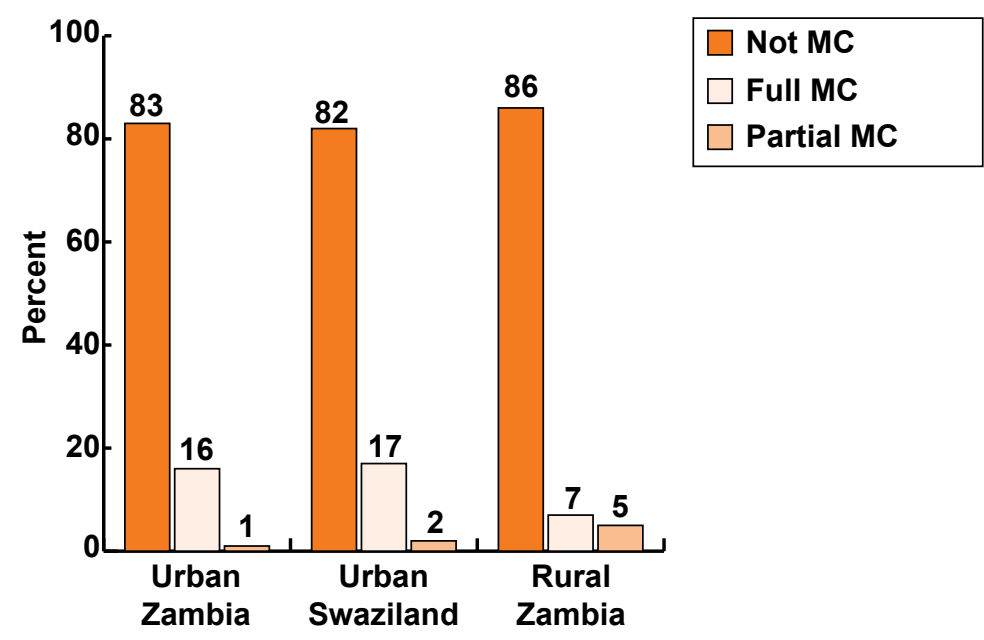

To investigate the differences in reporting of MC status by interview mode, participants were classified as correctly or incorrectly reporting their own or their partner's status using the classification scheme in Table 5. Although "don't know" (DK) could be interpreted as an incorrect response, for the following analysis these cases have been coded as missing and percentages noted separately (Table 6); this has little effect on the analysis for males, as very few males report not knowing their MC status (less than 1 percent of adult men and 3 percent of adolescent boys). For women, 8 percent in urban Zambia, 5 percent in urban Swaziland, and 3 percent in rural Zambia reported not knowing their partner's MC status.

Table 5. Classification schematic of MC status ${ }^{\dagger}$

\begin{tabular}{lc|c|c} 
& \multicolumn{2}{c}{ Participants' reported circumcision status } \\
Clinical assessment of circumcision status & No & Yes & DK \\
Not & & & \\
Complete & Correct & Incorrect & Missing \\
Partial & Incorrect & Correct & Missing \\
\end{tabular}

${ }^{\dagger}$ Assumes that the clinician's assessment is correct. 


\section{Misreporting of Circumcision Status}

Focusing first on urban Zambia, the top panel of Table 6 indicates that adult males have relatively low misreporting levels ( 3 percent on average). The percentage misreporting circumcision status is significantly higher among adolescents $(7$ percent, $\mathrm{p}<.05)$ and female partners $(11$ percent, $\mathrm{p}<.01)$; compared with male reports of not knowing their status, female partners are significantly more likely to indicate that they do not know their partner's status ( 8 percent, $\mathrm{p}<.01$ ). For Lusaka, there are no significant differences in misreporting of MC status by experimental group; these descriptive results indicate no improvement in reporting of $\mathrm{MC}$ either when an illustration is provided or in the case of audio computer-assisted self-interviews.

In urban Swaziland, the proportion misreporting among adolescents and adult men is the same (6 percent), while female partners have two and a half times the level of misreporting (15 percent, $\mathrm{p}<.01)$ as males. Contrary to expectations, misreporting is higher with ACASI than with FTFI, although significantly so only for the adolescent sample. The consistent pattern of higher misreporting of MC status in ACASI suggests that the privacy and confidentiality afforded by computerized interviewing does not improve, and potentially compromises, the reporting of MC status. As mentioned previously, because of the poor performance of ACASI in urban Swaziland and Zambia, this mode was not further evaluated in rural Zambia.

The patterns of misreporting for rural Zambia are similar to those in urban Zambia and Swaziland, with significant differences in misreporting observed by sex (6 percent males versus 12 percent females, $\mathrm{p}<.01$ ), but not by interview method for either males or females. Overall, the level of misreporting for adult males is marginally higher in rural Zambia than in Lusaka ( 6 percent versus 3 percent, $\mathrm{p}=.047$ ). But there is no difference in the misreporting level when comparing women's reports of partner status in Lusaka with those from rural Zambia (11 percent versus 12 percent). 
Table 6. Misreporting of MC status by site, sample group, study arm

\begin{tabular}{|c|c|c|c|}
\hline & \multirow[b]{2}{*}{$\begin{array}{c}\text { Males 13-17 } \\
\%\end{array}$} & \multicolumn{2}{|c|}{ Couples } \\
\hline & & $\begin{array}{c}\text { Males 18-50 } \\
\%\end{array}$ & $\begin{array}{c}\text { Females 18-50 } \\
\%\end{array}$ \\
\hline Urban Zambia & $N=300$ & $N=315$ & $N=293$ \\
\hline Full sample & 7 & 3 & 11 \\
\hline FTFI simple description & 7 & 1 & 11 \\
\hline FTFI SD + illustration & 5 & 5 & 10 \\
\hline ACASI SD + illustration & 9 & 3 & 11 \\
\hline Percent DK & 3 & 1 & 8 \\
\hline Urban Swaziland & $N=372$ & $N=362$ & $N=343$ \\
\hline Full sample & 6 & 6 & 15 \\
\hline FTFI detailed description & 2 & 6 & 16 \\
\hline FTFI DD + illustration & 4 & 4 & 13 \\
\hline ACASI DD + illustration & $11^{*}$ & 7 & 17 \\
\hline Percent DK & $<1$ & $<1$ & 5 \\
\hline Rural Zambia & - & $N=438$ & $N=425$ \\
\hline Full sample & - & 6 & 12 \\
\hline FTFI no description & - & 6 & 14 \\
\hline FTFI detailed description & - & 8 & 12 \\
\hline FTFI DD + illustration & - & 5 & 10 \\
\hline Percent DK & - & $<1$ & 3 \\
\hline
\end{tabular}

Notes: FTFI = face-to-face interview; $\mathbf{A C A S I}$ = audio computer-assisted self-interview.

${ }^{*} \mathrm{p}<.05$ (significance indicated for comparisons by interview mode only)

Although relatively few in number, the level of "don't know" cases varies significantly by interview method. In three of the six comparisons (by site and sex), a larger percentage of don't know responses occurs in the ACASI mode than in face-to-face interviews (data not shown). These differences are significant at the $\mathrm{p}<.01$ level for males in urban Zambia and for females in urban Swaziland and rural Zambia. It appears that when provided the opportunity to admit ignorance of MC status, participants are more apt to do so in a computerized interview than a face-to-face interview. As suggested by Table 6, however, when "Circumcised" or "Not Circumcised" status is reported in ACASI, it is not necessarily more accurate than in the FTFI.

The level of misreporting is informative, but the direction of bias in reporting should also be examined. The directional bias is indicated in Figure 3 for males and females separately. If misreporting is independent of MC status, the overall prevalence of MC in nationally representative surveys would not be affected, since misreporting in one direction would offset misreporting in the other direction (although such misreporting would lead to higher standard errors in estimates using MC status as an indicator). If the bias in reporting were to favor one direction over another, national estimates of prevalence would either be over or under estimates of actual prevalence. Given MC's potential impact on the spread of HIV, accurate estimates of MC are important for estimating and modeling HIV risk and for projecting prevalence and incidence in the population.

As can be observed in Figure 3, with the exception of rural Zambia for males, the bias in reporting of MC status is largely unidirectional, with uncircumcised men more often reporting that they are circumcised: 7 percent in Lusaka; 5 percent in Swaziland, and 2 percent in rural Zambia. Very few circumcised men in Lusaka and Swaziland misrepresent their MC status. In 
Figure 3. Direction of misreporting of MC status

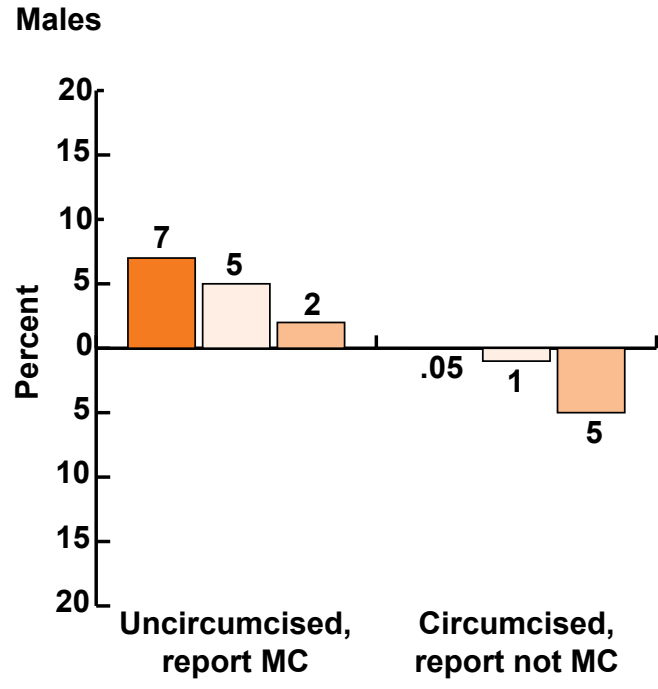

Females

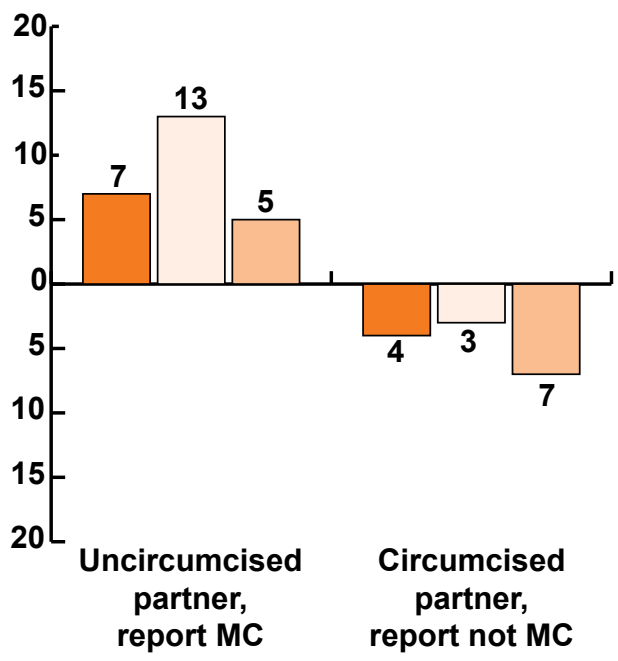

Urban Zambia $\square$ Urban Swaziland $\square$ Rural Zambia

rural Zambia, 5 percent of men classified as circumcised reported that they were not circumcised. This result, however, is primarily explained by the fact that a clinical officer who joined the study in rural Zambia was more inclined to classify men as partially circumcised ( 15 of the 22 partial MCs are attributable to one clinician). Although there is no way to confirm whether the designation by the clinical officer was in error, misclassification of circumcision status among clinicians is not uncommon (Diseker et al. 2001). ${ }^{2}$ With these cases removed from the total, only 2 percent of the circumcised men in rural Zambia report that they are uncircumcised, rates similar to those found at the other study sites.

As can be observed in the figure, misreporting among women is significantly higher than among men and the bias runs in both directions. The highest misreporting (13 percent) comes from Swazi women with uncircumcised partners. Misreporting among women is roughly double that of males in Swaziland. Further, as indicated in Table 6, a significantly higher percentage of women than men do not know their partner's status (Table 6). Overall, these findings reveal a high degree of misunderstanding among women about the circumcision status of their partners

By averaging the directional misreporting, we can determine the overall bias in estimates of MC prevalence. Our results indicate that to the extent that the samples are at all representative, surveys among males are likely to overestimate the prevalence of $\mathrm{MC}$ by approximately 4 percent (CI: 2 percent to 5 percent) in Zambia and 5 percent (CI: 3 percent to 6 percent) in Swaziland. ${ }^{3}$ For females, MC prevalence would be overestimated by approximately 3 percent (CI: 1 percent to 6 percent) in Zambia and 10 percent (CI: 6 percent to 14 percent) in Swaziland. As already noted, in addition to the potential bias in $\mathrm{MC}$ estimates, inaccuracies in reporting will also lead to a lack of precision in both descriptive and multivariate analyses incorporating MC status.

${ }^{2}$ It is possible that these men had naturally shorter foreskins, which would explain the appearance of partial circumcision even if the participant was not circumcised.

${ }^{3}$ Men who were classified as partially circumcised were removed from the estimate for rural Zambia. 


\section{Multivariate Assessment of Interview Methods}

To further assess whether the experimental arms of the study significantly reduced the prevalence of misreporting after adjusting for potential confounding factors, logistic regression models were estimated. The dependent variable was coded 1 if the participant misreported circumcision status (in either direction) and 0 if reported circumcision status was consistent with the clinician's assessment. The participant's demographic characteristics (see Table 2), as well as illiteracy, ever use of condoms, previously having heard of MC, and comprehensive knowledge of HIV prevention techniques, were used in the adjusted logistical model. The results of the regressions for each experimental arm by study site are indicated in Table 7; results of the influence of covariates are discussed below but are not shown.

\section{Table 7. Logistic regression assessing interview method on misreporting of MC status}

\begin{tabular}{|c|c|c|c|c|} 
& \multicolumn{2}{|c|}{ Males } & \multicolumn{2}{c}{ Females } \\
& OR & AOR & OR & AOR \\
Urban Zambia & $\mathbf{N}=\mathbf{6 1 5}$ & $\mathbf{N}=\mathbf{5 9 1}$ & $\mathbf{N}=\mathbf{2 9 3}$ & $\mathbf{N}=\mathbf{2 8 4}$ \\
FTFI simple description (Ref) & 1.00 & 1.00 & 1.00 & 1.00 \\
FTFI SD + illustration & 1.40 & 1.50 & 0.91 & 0.82 \\
ACASI SD + illustration & 1.70 & 1.80 & 0.94 & 0.79 \\
Urban Swaziland & $\mathbf{N}=\mathbf{7 3 4}$ & $\mathbf{N}=\mathbf{7 0 0}$ & $\mathbf{N}=\mathbf{3 4 3}$ & $\mathbf{N}=\mathbf{3 3 2}$ \\
FTFI detailed description (Ref) & 1.00 & 1.00 & 1.00 & 1.00 \\
FTFI DD + illustration & 0.98 & 1.00 & 0.81 & 0.80 \\
ACASI DD + illustration & $2.30^{*}$ & $2.30^{* *}$ & 1.10 & 1.10 \\
Rural Zambia & $\mathbf{N}=\mathbf{4 1 6}$ & $\mathbf{N}=\mathbf{4 0 2}$ & $\mathbf{N}=\mathbf{4 0 3}$ & $\mathbf{N}=\mathbf{3 9 8}$ \\
FTFI no description (Ref) & 1.00 & 1.00 & 1.00 & 1.00 \\
FTFI detailed description & 1.00 & $0.61^{* *}$ & 0.77 & $0.63^{* *}$ \\
FTFI DD + illustration & 1.30 & 1.10 & 0.78 & 0.91 \\
\hline
\end{tabular}

${ }^{\dagger} p<.10,{ }^{*} p<.05,{ }^{* *} p<.01$

Notes: OR: odds ratio; AOR: adjusted odds ratio: adjusted for demographic variables in Table 2, as well as having previously heard of MC, comprehensive knowledge of HIV prevention, and ever use of condom. Standard errors adjusted for clustering within interview method for AOR models; Ref: reference or base category.

${ }^{ \pm}$Dropped cases in which clinician indicated partial circumcision $(N=44)$-see text above.

The unadjusted and adjusted odds ratios indicate results similar to those observed in Table 6 , although the differences in rural Zambia become more pronounced and in some cases significant when partial MC cases are removed. The similarity between the unadjusted and adjusted odds ratios suggests that the randomization was largely effective in assuring independence between the participant characteristics and interview mode. As with the descriptive findings, men in Swaziland using the ACASI mode had over twice the odds of misreporting as those in the FTFI mode. The pattern of higher misreporting in ACASI is also evident among males in urban Zambia, but is not significant. In rural Zambia (the only setting in which a detailed description and illustration were compared with current practice, which involves no description), male and female participants receiving a more detailed verbal description of circumcision had significantly lower odds of misreporting when other factors were controlled for and standard errors were adjusted for clustering by experimental arm. Unexpectedly, reductions in misreporting were not apparent among males in rural Zambia who received both a detailed description and an illustration. For females in rural Zambia, showing the illustration with the detailed description also improved reporting, but not significantly. Few demographic or other characteristics were found to be consistently significant: older age lowered misreporting for males in both urban and rural Zambia 
( $\mathrm{p}<.05)$, while illiteracy increased misreporting $(\mathrm{p}<.01)$ among females in rural Zambia; also, being married increased the odds of misreporting $(\mathrm{p}<.01)$ among females in Lusaka.

\section{Multivariate Assessment of IIlustration}

Although the experimental arms did not consistently reveal improvement in the reporting of MC status, one additional issue investigated was whether the illustrations reduced misreporting, particularly for those who were not able to read a simple sentence. To assess this question, the data were pooled across all sites and by sex, and two regression models were estimated. The first model estimates the impact of the illustration separately for literate and illiterate participants (top panel of Table 8). The odds ratios of this model have the conventional interpretation. To assess the statistical significance of interaction between literacy and the illustration, a second logistic regression model was estimated (bottom panel of Table 8). Unlike linear models in which the interaction term reflects the change in impact of one explanatory variable on the outcome for a unit change in the other, in non-linear models the marginal effect cannot be similarly computed or interpreted (Buis 2010; Norton, Wang, and Ai 2004). Thus, to provide a more substantive interpretation of the results, the odds of misreporting for each combination of the interaction are also provided (Buis 2010).

Table 8. Pooled logistic regression assessing illustration of a circumcised and uncircumcised penis on misreporting of MC status

\begin{tabular}{|c|c|c|c|c|}
\hline \multirow[b]{2}{*}{ Separate model } & \multicolumn{2}{|c|}{$\begin{array}{l}\text { Literate participants } \\
\qquad(\mathrm{N}=2226)\end{array}$} & \multicolumn{2}{|c|}{$\begin{array}{l}\text { Illiterate participants } \\
\qquad(\mathrm{N}=560)\end{array}$} \\
\hline & OR & AOR & OR & AOR \\
\hline $\begin{array}{l}\text { Illustration of MC provided } \\
\text { ACASI } \\
\text { Study site: Urban Zambia } \\
\text { Study site: Rural Zambia }\end{array}$ & $\begin{array}{l}1.00 \\
1.50^{\dagger}\end{array}$ & $\begin{array}{l}1.10^{* *} \\
1.40^{* *} \\
0.52^{\star *} \\
0.28^{\star *}\end{array}$ & $\begin{array}{l}0.66 \\
1.20\end{array}$ & $\begin{array}{l}0.62^{\star *} \\
1.30^{\dagger} \\
2.30 \\
2.10^{\dagger}\end{array}$ \\
\hline $\begin{array}{l}\text { Female } \\
\text { Age (continuous) } \\
\text { Attended primary or lower } \\
\text { Married or living with partner }\end{array}$ & & $\begin{array}{l}2.50^{* *} \\
0.98^{\dagger} \\
1.20 \\
1.30\end{array}$ & & $\begin{array}{l}4.60^{* *} \\
0.97^{* *} \\
0.84 \\
0.42^{* *}\end{array}$ \\
\hline $\begin{array}{l}\text { Comprehensive HIV knowledge } \\
\text { Ever heard of MC } \\
\text { Ever used condom }\end{array}$ & & $\begin{array}{l}0.82 \\
0.67 \\
1.20\end{array}$ & & $\begin{array}{l}0.77^{\dagger} \\
1.50 \\
1.40\end{array}$ \\
\hline Interaction model ${ }^{ \pm}$ & \multicolumn{2}{|c|}{ Coefficient } & SE & p-value \\
\hline Interaction: Illiterate* illustration & \multicolumn{2}{|c|}{-.045} & 0.01 & $<0.01$ \\
\hline \multicolumn{5}{|l|}{ Odds of misreporting ${ }^{ \pm}$} \\
\hline Illiterate and no illustration & \multicolumn{2}{|c|}{.13} & & \\
\hline Illiterate and illustration & \multicolumn{2}{|c|}{.10} & & \\
\hline Literate and no illustration & \multicolumn{2}{|c|}{.06} & & \\
\hline Literate and illustration & \multicolumn{2}{|c|}{.08} & & \\
\hline
\end{tabular}

${ }^{\dagger} \mathrm{p}<.10,{ }^{*} \mathrm{p}<.05,{ }^{* *} \mathrm{p}<.01$

Notes: OR: odds ratio; AOR: adjusted odds ratio and significance tests. Tribal affiliation included in model, but results not shown. Standard errors adjusted for clustering within interview mode. Models do not include cases of partial circumcision. ثStatistical computation based on approach by Norton, Wang, and Ai 2004; includes full set of covariates (results not shown). Odds of misreporting based on estimation approach suggested by Buis 2010. 
As seen in the top panel of Table 8 , the effect of the illustration differs between literate and illiterate participants. In the unadjusted model, the OR for the illustration group is not significant and reveals no differences relative to the reference group. For the AOR, however, the results become statistically significant when covariates are included and standard errors are adjusted for clustering by interview method. The counterintuitive and slightly positive impact on increased misreporting by literate participants with the addition of an illustration (a marginal increase of 10 percent on the odds of misreporting) is puzzling at first glance. However, the question was raised as to whether the original illustration used in Lusaka was sufficiently clear since part of the glans was revealed in the uncircumcised penis. When the Lusaka data are excluded from the analysis, the illustration significantly reduces misreporting among both illiterate and literate participants (data not shown). For illiterate participants, the illustration reduces the odds of misreporting by 34 percent in the OR and by 38 percent in the AOR models, again with the result significant only in the adjusted estimation. ${ }^{4}$ The effect of the illustration by literacy status is confirmed in the model that reveals a significant interaction term at $\mathrm{p}<.01$ (bottom panel of Table 8). Further, the odds of misreporting for each sub-category of participant indicate that the greatest difference in the prevalence of misreporting is between illiterate and literate participants when no illustration is provided, an illustration reducing by 3 percent the misreporting by illiterate participants.

The top panel of Table 8 also indicates some additional factors associated with the misreporting of circumcision status. For instance, participants using ACASI have significantly greater odds of misreporting their MC status than those interviewed face-to-face. Further, literate females have over 2.5 times the odds and illiterate females over 4.5 times the odds of misreporting relative to males. Study participants in Zambia, older participants, and participants who are married or living with their partner are less likely to misreport. Interestingly, knowledge of HIV prevention methods, having heard of MC, and ever having used a condom do not reveal consistent or significant effects, although comprehensive knowledge reduces the odds of misreporting among illiterates $(\mathrm{p}<.10)$

${ }^{4} \mathrm{An}$ interaction model that focused exclusively on the impact of an illustration for female participants did not reveal a significant reduction in the misreporting of MC status. 


\section{CONCLUSIONS AND RECOMMENDATIONS}

The primary objective of this study was to provide evidence-based recommendations for the collection of self-reported data on MC status to researchers and program managers interested in measuring the prevalence of male circumcision in the population via household surveys. It also informs HIV prevention trials that include female participants, given the need to identify the circumcision status of their partners as a risk factor for HIV/STIs. The study assessed various tools for improving the reporting of circumcision status, including a) a simple and a more detailed verbal description of male circumcision, b) an illustration of a circumcised and an uncircumcised penis, and c) computerized self-interviewing technology.

Between 3 and 7 percent of males in the study misreported their circumcision status judging by a clinical exam. For males the bias in reporting of MC status is largely unidirectional, with uncircumcised men reporting that they are circumcised; few circumcised men misrepresented their MC status. These results suggest that the prevalence of MC may be overestimated by approximately 4 percent in Zambia and 5 percent in Swaziland. This represents a significant fraction of the MC prevalence currently reported in both countries: 13 percent in Zambia (CSO 2010) and 8 percent in Swaziland (CSO 2008). In addition, when assessing the influence of $\mathrm{MC}$ on HIV incidence, estimates of the impact of MC are likely to be attenuated given the misreporting. These results indicate that inaccurate self-reports of MC status are a concern in Zambia and Swaziland, which parallels findings from other countries (e.g., Weiss et al. 2008; Urassa et al. 1997; Risser et al. 2004; Schlossberger et al. 1991; Thomas et al. 2010).

Between 11 and 15 percent of women did not accurately report the circumcision status of their partners, with the bias in reporting in both directions. Clinical trials testing potential HIV prevention technologies and behavioral interventions rely alike on women's reports of their partner's $\mathrm{MC}$ status to control for confounding effects of $\mathrm{MC}$ in analyses of secondary endpoints. The accurate measurement of other HIV risk and protective factors in observational studies with women participants will also be undermined if inaccurate partner reports of circumcision status are trusted.

To improve reporting, this study sought to address (1) issues involving lack of knowledge by introducing two verbal descriptions of circumcision as well as an illustration of a circumcised and an uncircumcised penis, and (2) social desirability bias, through the use of ACASI. It also sought to assess the acceptability of physical examination by a trained clinical officer to verify MC status. The study found that it is feasible and acceptable to use a detailed description and/ or illustration of $\mathrm{MC}$ with little negative feedback from the population. The study did, however, find that a significant percentage (30 percent) of participants in urban Lusaka were not inclined to participate in the physical examination, despite the fact that the exam took place in a health care setting. This result suggests that researchers contemplating studies that rely on physical examination at the household level should anticipate the potential for problems (see also Westercamp 2010).

The study results indicated that the ACASI method does not improve, and likely compromises, the self-reporting of MC status. The poor performance of ACASI suggests that participants felt a greater obligation to respond honestly to an interviewer, implying that social desirability bias is probably not a factor in misreporting of MC. It should be noted, however, that social desirability

bias may become more of an issue as MC programs are scaled-up, mass media messaging becomes pervasive, and circumcision becomes more normative. It is also possible that in the event of 
uncertainty, face-to-face interviews provided a greater opportunity for the interviewer and participant to discuss the nature of circumcision; interviewers were not prohibited from assisting participants if the participant asked for additional clarification or explanation.

The study found that providing an illustration for illiterate participants improves reporting of MC status: misreporting among illiterate participants declined from 13 percent without an illustration to 10 percent when one was provided. Counterintuitively, the results indicate that misreporting was more common among literate participants when they were given an illustration; however, the regression results indicate that the results were not as substantial as the reduction in misreporting for illiterate participants. Moreover, this anomaly disappears when the data from urban Zambia - where an inferior illustration was used-are dropped from the analysis. The overall conclusion to be drawn is that illustrations provide a useful method for improving the reporting of $\mathrm{MC}$ status by both males and females.

There are limitations to this study that should be considered when interpreting results. A key concern is that the sample is not representative of the Zambian and Swazi populations and hence the prevalence estimates of misreporting relative to the overall prevalence of $\mathrm{MC}$ in each country need to be interpreted with caution. However, similarities in misreporting prevalence between this study and others conducted in Africa provide confirmation that estimates of circumcision prevalence are overestimated. A second consideration is that as MC programs scale up and messages about the benefits of $\mathrm{MC}$ reach a larger proportion of people, there may be changes to misreporting in two offsetting ways: on the one hand, a potential decrease in any misreporting caused by a lack of understanding of MC; on the other hand, a potential increase in misreporting because of increased social desirability bias. The results of this study, therefore, may be most relevant to countries with relatively low prevalence of $\mathrm{MC}$ and where $\mathrm{MC}$ programs have not reached a national scale.

This study echoes others that suggest misreporting of $\mathrm{MC}$ status is a concern for researchers and program managers interested in measuring the prevalence of $\mathrm{MC}$ or using $\mathrm{MC}$ status as an indicator in models of HIV/STI outcomes. It is the first study to our knowledge that has looked at female misreporting of partner MC status. The study suggests that errors in reporting occur for both males and females and have the potential to skew prevalence studies as well as mask positive effects of prevention interventions. To compensate, providing an illustration along with a detailed description of MC may help improve self- and partner reports of MC, particularly among illiterate populations. 


\section{APPENDIX A \\ STUDY SAMPLE SIZES BY KEY INDICATORS}

\begin{tabular}{|c|c|c|c|c|c|c|}
\hline Lusaka sample & \multicolumn{2}{|c|}{ Adolescent sample } & \multicolumn{2}{|c|}{ Adult males } & \multicolumn{2}{|c|}{ Adult females } \\
\hline Study arm & \multicolumn{2}{|c|}{$\mathbf{N}=438$} & \multicolumn{2}{|c|}{$N=420$} & \multicolumn{2}{|c|}{$N=420$} \\
\hline FTFI - no illustration & \multicolumn{2}{|c|}{145} & \multicolumn{2}{|c|}{147} & \multicolumn{2}{|c|}{147} \\
\hline FTFI - illustration & \multicolumn{2}{|c|}{154} & \multicolumn{2}{|c|}{146} & \multicolumn{2}{|c|}{146} \\
\hline \multirow[t]{3}{*}{ ACASI - illustration } & \multicolumn{2}{|c|}{139} & \multicolumn{2}{|c|}{127} & \multicolumn{2}{|c|}{127} \\
\hline & \multicolumn{2}{|c|}{ Physical exam } & \multicolumn{2}{|c|}{ Physical exam } & \multicolumn{2}{|c|}{ Physical exam ${ }^{1}$} \\
\hline & No & Yes & No & Yes & No & Yes \\
\hline \multicolumn{7}{|l|}{ Reported MC status } \\
\hline Not circumcised & 119 & 242 & 91 & 233 & 78 & 214 \\
\hline Circumcised & 5 & 58 & 10 & 82 & 17 & 79 \\
\hline Don't know & 3 & 10 & 1 & 3 & 7 & 25 \\
\hline Missing & 0 & 1 & 0 & 0 & 0 & 0 \\
\hline Total sample & 127 & 311 & 102 & 318 & 102 & 318 \\
\hline Analytic sample $^{2}$ & & 300 & & 315 & & 293 \\
\hline Swaziland sample & \multicolumn{2}{|c|}{ Adolescent sample } & \multicolumn{2}{|c|}{ Adult males } & \multicolumn{2}{|c|}{ Adult females } \\
\hline Study arm & \multicolumn{2}{|c|}{$N=402$} & \multicolumn{2}{|c|}{$N=401$} & & \\
\hline FTFI - no illustration & & & & & & \\
\hline FTFI - illustration & & & & & & \\
\hline ACASI - illustration & & & & & & \\
\hline & Phy & xam & Phys & xam & Phys & $x m^{1}$ \\
\hline & No & Yes & No & Yes & No & Yes \\
\hline Reported MC status & & & & & & \\
\hline Not circumcised & 16 & 305 & 23 & 264 & 24 & 231 \\
\hline Circumcised & 5 & 67 & 11 & 98 & 8 & 112 \\
\hline Don't know & 0 & 2 & 0 & 3 & 1 & 17 \\
\hline Missing & 0 & 7 & 0 & 2 & 1 & 7 \\
\hline Total sample & 21 & 381 & 34 & 367 & 34 & 367 \\
\hline Analytic sample $^{2}$ & & 372 & & 362 & & 343 \\
\hline Rural Zambia sample & Adole & sample & Adt & ales & Adu & ales \\
\hline Study arm & & & & & & \\
\hline FTFI - no illustration & & & & & & \\
\hline FTFI - illustration & & & & & & \\
\hline ACASI - illustration & & & & & & \\
\hline & Phy & xam & Phys & xam & Phys & $\operatorname{xam}^{1}$ \\
\hline & No & Yes & No & Yes & No & Yes \\
\hline Reported MC status & & & & & & \\
\hline Not circumcised & - & - & 4 & 390 & 4 & 372 \\
\hline Circumcised & - & - & 0 & 48 & 0 & 53 \\
\hline Don't know & - & - & 0 & 1 & 0 & 14 \\
\hline Missing & - & - & 0 & 0 & 0 & 0 \\
\hline Total sample & - & - & 4 & 439 & 4 & 439 \\
\hline Analytic sample ${ }^{2}$ & - & - & & 438 & & 425 \\
\hline
\end{tabular}

${ }^{1}$ Based upon the physical examination of partner; ${ }^{2}$ Excluding don't know and missing cases from reported MC status. 


\section{APPENDIX B \\ DESCRIPTION OF AUDIO COMPUTER-ASSISTED SELF-INTERVIEW (ACASI)}

The software used for ACASI was a customized system developed by the Population Council using Windows-based development tools using the .NET framework with C\# programming language. ACASI software can be used on multiple hardware platforms, including tablet computers, handhelds, desktops, and notebooks.

The ACASI program allows participants to hear the questions and response options through headphones, while also reading the associated text on the computer screen. The participant has the option of listening to the questionnaire in the local languages or in English. In this study two local languages were used in Zambia (Nyanja and Bemba) and one in Swaziland (SiSwati). The participant answers questions by pressing a picture, color, or number associated with a response option on the computer screen. Although the text is displayed on the computer screen, literacy is not required to complete the questionnaire, since the participant can listen to the question and response options; recognition of numbers, however, was necessary to complete the full questionnaire.

An example of a screen view for one of the questions in the survey is displayed below:

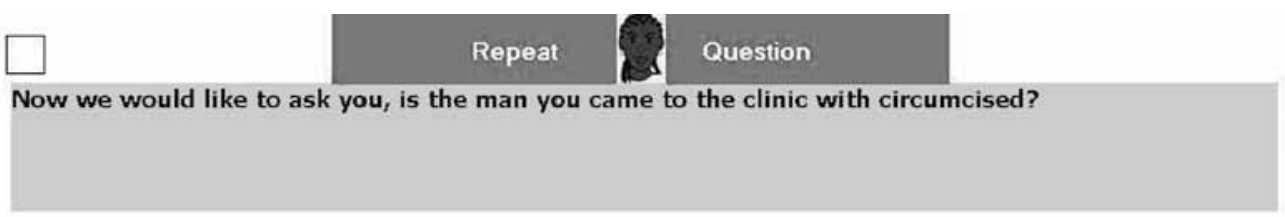

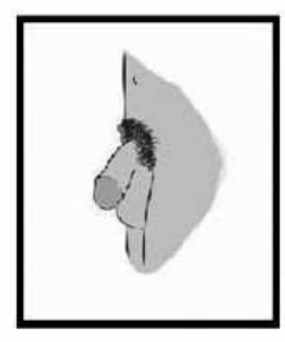

Circumcised penis

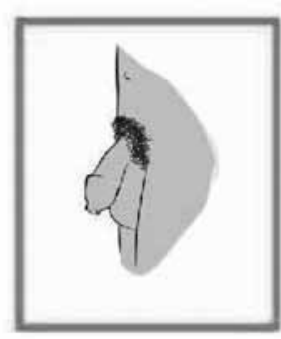

Uncircumcised penis

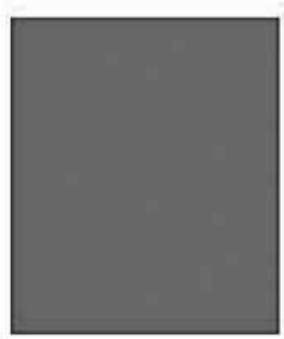

Do not know

Previous

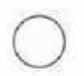




\section{APPENDIX C LITERACY AND NUMERACY EVALUATION}

\section{Literacy Assessment}

The literacy assessment entailed giving the participant a laminated card with one of the following sentences on it and asking him or her to read the sentence aloud. The interviewer then coded the ability to read as a) able to read full sentence, b) able to read part of sentence, c) not able to read any part of sentence. The participant was subsequently coded as literate if he or she could read the full sentence. In Swaziland, the participant was given the option of reading the sentence in SiSwati if s/he preferred.

\begin{tabular}{ll}
\multicolumn{1}{c}{ English } & \multicolumn{1}{c}{ SiSwati } \\
Parents love their children. & Batali bayabatsandza bantfwana babo. \\
Farming is hard work. & Kufuya kungumsebenti lolukhuni. \\
The child is reading a book. & Lomntfwana ufundza incwadzi. \\
Children work hard at school. & Bantfwana basebenta kalukhuni esikolweni.
\end{tabular}

\section{Numeracy Assessment}

The numeracy assessment entailed giving the participant a laminated card with the following list of numbers and stating, "Now I would like you to read these numbers to me in the order that they are shown on the card." The participant was subsequently coded as having numeric ability if he or she was able identify all numbers accurately.

$\begin{array}{llllllllll}4 & 7 & 2 & 3 & 9 & 1 & 8 & 10 & 5 & 6\end{array}$ 


\section{APPENDIX D STUDY FIELDWORK TEAMS}

\section{Zambia}

\section{Project Coordinator}

Kelvin Munjile*

\section{Enumerators}

Clemency Banda

James Banda

Chilele Kolala

Kangwa Kabamba

Mulenga Kaemba

Walumweya Mubitana

Max Mupale

Tamara Mwandila ${ }^{\dagger}$

Elina Nambeye ${ }^{\dagger}$

Patrick Nawa

Shimeo Sakanya

\section{Clinical Officers}

Chansa Chipili

Alloys Mugema

\section{Swaziland}

\section{Project Coordinator}

Alfred Adams*

\section{Enumerators}

Nomcebo Fakudze

Sabelo Gamedze

Ziyanda Matholeni ${ }^{\dagger}$

Linganiso Mavinbela

Lomagugu Shabangu

\section{Clinical Officers}

Dr. Abiodun Lamina

Mcebisi Sukati 


\section{REFERENCES}

Auvert, Bertran et al. 2005. "Randomized, controlled intervention trial of male circumcision for reduction of HIV infection risk: The ANRS 1265 trial," PLoS Med 2(11): e298: 1112-1122.

Bailey, Robert et al. 2007. "Male circumcision for HIV prevention in young men in Kisumu, Kenya: a randomised controlled trial," Lancet 369: 643-656.

Booth-Keweley, S., G.E. Larson, and D.K. Miyoshi. 2007. "Social desirability effects on computerized and paperand-pencil questionnaires," Computers in Human Behavior 23: 463-477.

Bophelo Pele Centre. Unpublished. "Bophelo Pele Male Circumcision Research.” Accessed March 16, 2011

http://www.bpmcc.co.za/research.htm.

Brown, Judith et al. 2001. "Varieties of male circumcision: A study from Kenya," Sexually Transmitted Diseases 28(10): 608-612.

Buckner, B., K. Singh, and J. Tate. 2006. Zambia Sexual Behaviour Survey 2005. Central Statistical Office, Ministry of Health, MEASURE Evaluation. www.cpc.unc.edu/measure.

Buis, M. 2010. “Interpretation of interactions in non-linear models” Stata Journal 10(2): 305-308.

Castellsagué, Xavier et al., for the International Agency for Research on Cancer Multicenter Cervical Cancer Study Group. 2002. "Male circumcision, penile human papilloma virus infection, and cervical cancer in female partners," The New England Journal of Medicine 346(15): 1105-1112.

Central Statistical Office (CSO) [Swaziland], and Macro International Inc. 2008. Swaziland Demographic and Health Survey 2006-07. Mbabane, Swaziland: Central Statistical Office and Macro International Inc. Accessed March 30, 2011 http://www.measuredhs.com/pubs/pdf/FR202/FR202.pdf.

Central Statistical Office (CSO) et al. 2009. Zambia Demographic and Health Survey 2007. Calverton, Maryland, USA: CSO and Macro International Inc. Accessed March 30, 2011 http://www.measuredhs.com/pubs/pdf/ FR211/FR211[revised-05-12-2009].pdf.

Central Statistical Office (CSO) et al. 2010. Zambia Sexual Behaviour Survey 2009. Lusaka, Zambia: CSO and MEASURE Evaluation. Accessed March 15, 2011 http://www.cpc.unc.edu/measure/publications/tr-10-73.

Diseker, R. A. et al. 2001. "Fleeting foreskins: the misclassification of male circumcision status," Sexually Transmitted Diseases 28(6): 330-335.

Gray, Ronald et al. 2007. "Male circumcision for HIV prevention in men in Rakai, Uganda: a randomised controlled trial," Lancet 369: 657-666.

Hewett, P. C. et al. 2008. "Using sexually transmitted infection biomarkers to validate reporting of sexual behavior within a randomized, experimental evaluation of interviewing methods," American Journal of Epidemiology 168(2): 202-211.

Lavreys, Ludo et al. 1999. "Effect of circumcision on incidence of Human Immunodeficiency Virus Type 1 and other sexually transmitted diseases: A prospective cohort study of trucking company employees in Kenya," The Journal of Infectious Diseases 180: 330-336. 
Mensch, Barbara et al. 2009. "Assessing the reporting of adherence and sexual activity in a simulated microbicide trial in South Africa: An interview mode experiment using a placebo gel.” Unpublished manuscript.

Mensch, Barbara et al. 2008. "Sexual behavior and STI/HIV status among adolescents in rural Malawi: An evaluation of the effect of interview mode on reporting," Studies in Family Planning 39(4): 321-334.

Ministry of Health (MOH), Zambia. 2010. National Male Circumcision Strategy and Implementation Plan $2010-$ 2020. http://www.malecircumcision.org/programs/documents/2010-2020NationalMCStrategyandImplementati onPlan.pdf

Norton, E.C., H. Wang and C. Ai. 2004. "Computing interaction effects and standard errors in logit and probit models," Stata Journal 4(2): 154-167.

Risser, Jan et al. 2004. "Self-assessment of circumcision status by adolescents," American Journal of Epidemiology 159(11): 1095-1097.

Schlossberger, Norman, Rebecca Turner, and Charles Irwin. 1991. "Early adolescent knowledge and attitudes about circumcision: Methods and implications for research," Journal of Adolescent Health 13(4): 293-297.

Thomas, Anne, M. Cranston, B. Tran, M. Brown, M. Tlelai, and R. Kumar. 2010. "Comparison of self-reported and physical examination based male circumcision prevalence rates in Lesotho," poster presentation at the $17^{\text {th }}$ Conference on Retroviruses and Opportunistic Infections, San Francisco, February 16-19.

Tourangeau, R et al. 2000. The Psychology of Survey Response. Cambridge: Cambridge University Press.

Urassa, Marc et al. 1997. "Male circumcision and susceptibility to HIV infection among men in Tanzania," AIDS 11(1): 73-80.

Weiss, Helen et al. 2008. "Circumcision among adolescent boys in rural northwestern Tanzania," Tropical Medicine and International Health 13(8): 1054-1061.

Westercamp, Matthew et al. 2010. "Male circumcision in the general population of Kisumu, Kenya: Beliefs about protection, risk behaviors, HIV and STIs,” PLoS ONE 5(12): e15552.

Wilkerson, James M., Dennis H Nagao, and Christopher L. Martin. 2002. "Socially desirable responding in computerized questionnaires: When questionnaire purpose matters more than the mode," Journal of Applied Social Psychology 32(2): 544-559.

Williams, Brian et al. 2006. "The potential impact of male circumcision on HIV in Sub-Saharan Africa," PLoS Med 3(7): e262.

WHO/UNAIDS. 2007. "New data on male circumcision and HIV prevention: Policy and programme implications," Conclusions and recommendations of the WHO/UNAIDS Technical Consultation, Montreux, Switzerland, 6-8 March. 



\section{(2) Population Council

www.popcouncil.org

\section{Population Council}

One Dag Hammarskjold Plaza

New York, New York 10017

USA

Telephone: +1 2123390500

Facsimile: +1 2127556052 